Editor's Note: Whereas the JPE editorial and production staff make every effort to preserve the integrity of each author's work, the occasional error occurs. In Vol. 16, No. 3, p.284-287 of the Supplemental Literature Review "Hf-Pd (Hafnium-Palladium)," "Ir-Sc (Iridium-Scandium)," and Pt-Si (Platinum-Silicon), the diagrams were incorrectly placed due to a printer error. The full text and correct diagrams are printed below.

\title{
Hf-Pd (Hafnium-Palladium)
}

\section{H. Okamoto}

The Hf-Pd phase diagram in [Massalski2] was redrawn from [72Shu]. Five compounds were reported: $\mathrm{Hf}_{2} \mathrm{Pd}, \mathrm{HfPd}$, and $\mathrm{HfPd}_{3}$, which form peritectically at 1415,1610 , and $1965^{\circ} \mathrm{C}$, respectively; $\mathrm{Hf}_{3} \mathrm{Pd}_{4}$, which forms peritectoidally at $1560{ }^{\circ} \mathrm{C}$; and $\mathrm{HfPd}_{2}$, which forms congruently at $2075^{\circ} \mathrm{C}$ and decomposes eutectoidally at $1370^{\circ} \mathrm{C}$.

This configuration was questioned by [94Sel] on the basis of enthalpy of formation measurements of the five compounds and an x-ray diffraction analysis of an alloy containing 75 at. \% Pd. The reactions observed by [94Sel] indicated that $\mathrm{HfPd}_{2}$ forms peritectically while $\mathrm{HfPd}_{3}$ forms congruently. A possible shape of the phase diagram in the range of 40 to 75 at.\% $\mathrm{Pd}$ was illustrated by [94Sel] (Fig. 1). The temperature scale is unknown. Furthermore, the enthalpy of formation values observed [94Sel] indicated that $\mathrm{Hf}_{3} \mathrm{Pd}_{4}$ and $\mathrm{HfPd}$, instead of $\mathrm{HfPd}_{2}$, may be unstable at low temperatures
[94Oka] questioned the slope of the $(\beta \mathrm{Hf}) /(\beta \mathrm{Hf})+(\alpha \mathrm{Hf})$ phase boundary and the liquidus and solidus trends of (Pd) in the HfPd phase diagram in [Massalski2]. In addition, the schematic configuration shown in Fig. 1 inevitably induces an unlikely asymmetric liquidus (see [93Oka]) for $\mathrm{HfPd}_{3}$ if the other part of the Hf-Pd diagram in [Massalski2] is assumed to be correct. Apparently, the entire phase diagram should be reinvestigated.

\section{Cited References}

72Shu: A.K. Shurin and V.V. Pet'kov, Russ, Metall, (2), 122-144 (1972).

93Oka: H. Okamoto and T.B. Massalski, J. Phase Equilibria, 14(3), 316-335(1993).

940ka: H. Okamoto and T.B. Massalski, J. Phase Equilibria, 15(5), 500-521 (1994).

94Sel: N. Selhaour, J.C. Gachon, and J. Hertz, J. Alloy. Compd., 204, 157-164(1994).

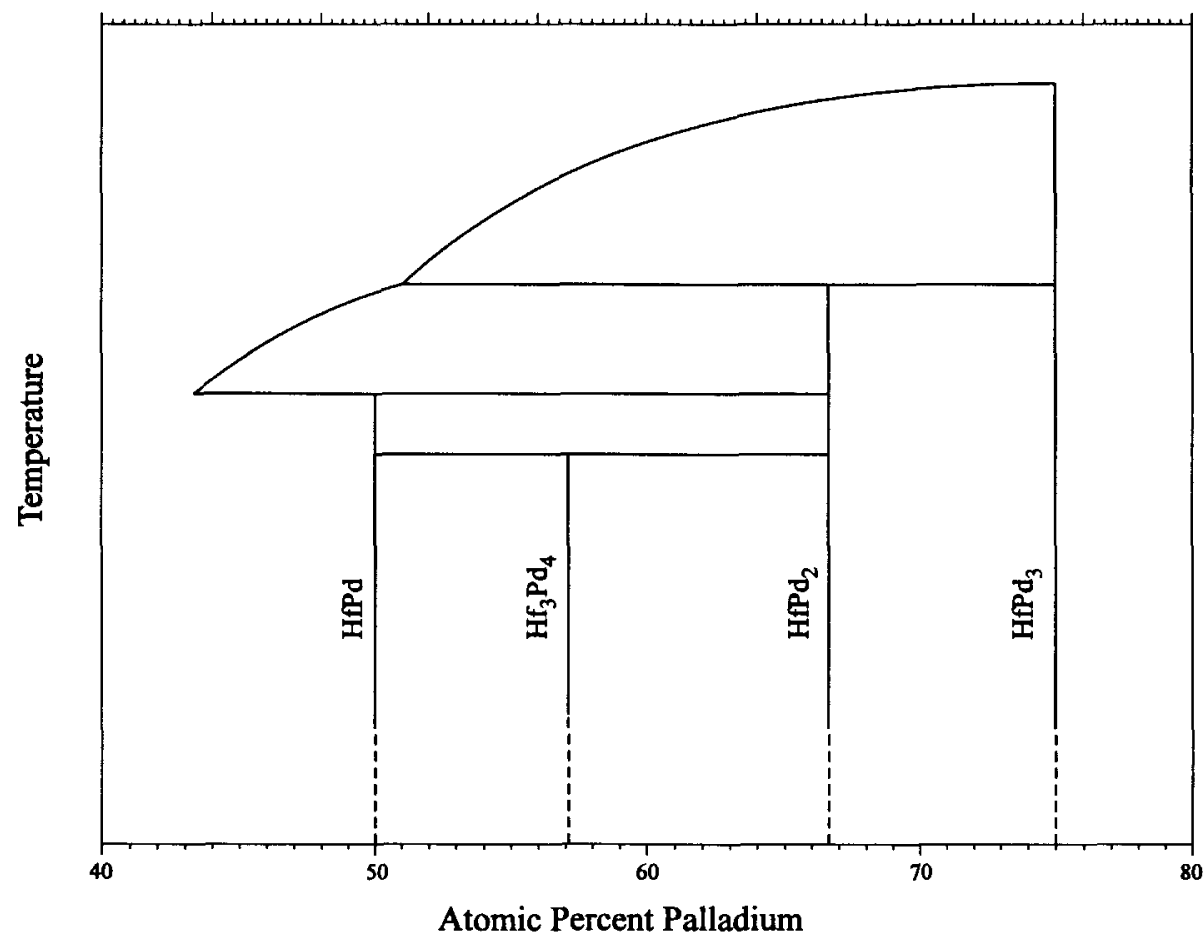

Fig. 1 Hf-Pd phase diagram. 